\title{
Titanium solar metallurgy - Earth and Space
}

\author{
Jaroslav Kováčik ${ }^{1, *}$, Natália Mináriková ${ }^{1}$, Štefan Emmer $^{2}$, Peter Šugár ${ }^{3}$, Jana Šugárová ${ }^{3}$, \\ Barbora Ludrovcová ${ }^{3}$, Amro Al-Qutub ${ }^{4}$, Khaled Al-Athel ${ }^{4}$, Jose Rodriguez ${ }^{5}$, and \\ Inmaculada Cañadas ${ }^{5}$ \\ ${ }^{1}$ Slovak Academy of Sciences, Institute of Materials and Machine Mechanics, Dúbravská cesta 9, 845 \\ 13 Bratislava, Slovakia \\ ${ }^{2}$ IVMA STU, Pionierska 15, 83102 Bratislava, Slovakia \\ ${ }^{3}$ Institute of Production Technologies, Faculty of Materials Science and Technology, Slovak \\ University of Technology, J. Bottu 25, 91724 Trnava, Slovakia \\ ${ }^{4}$ King Fahd University of Petroleum \& Minerals, Mechanical Engineering Department, 31261 \\ Dhahran, Saudi Arabia \\ ${ }^{5}$ PSA - Plataforma Solar de Almería, CIEMAT, Apartado 22, Ctra de Senes Km 4, 04200 Tabernas \\ (Almería), Spain
}

\begin{abstract}
Experimental results for solar metallurgy, solar powder metallurgy of titanium, solar surface treatment of titanium and titanium welding are briefly reviewed. Most of them were performed at Plataforma Solar de Almeria Spain using solar furnaces SF5 and SF40 in gas/vacuum furnace. Generally, it was observed that the time to achieve required sample temperature is very short when concentrated solar power used. Thanks to use of renewable solar energy these technologies starts to be attractive for industrial production of titanium in Earth solar belt. It can be expected that the obtained results and approaches are similar also in Space. According to the obtained knowledge, the possible solutions/necessary changes for solar furnaces on Moon, Mars and in main asteroids belt are discussed.
\end{abstract}

\section{Introduction}

NASA has massive Moon and Mars aspirations in next 20 years [1]. In December 2017, President Donald Trump gave NASA a new direction. NASA will work with international and commercial partners to refocus exploration efforts on the Moon, with an eye to going on to Mars and even beyond. Then the space agency released broad plans about its directive to get humans back on the lunar surface. It is expected that even private aerospace industry will assist in this Moon and Mars shots. The Moon campaign has four strategic goals:

- human spaceflight in low-Earth orbit transformed to commercial operations to support NASA and the needs of new emerging private sector market.

- extend duration of U.S. human spaceflight operations to lunar orbit.

- long-term robotic exploration of the Moon.

\footnotetext{
${ }^{*}$ Corresponding author: ummsjk@savba.sk
} 
- human exploration of the Moon as preparation for human missions to Mars and deeper into the solar system.

Between Lunar surface objectives it can be found a request for the long-term human exploration and exploitation of the lunar surface together with demand for aggressive characterization of lunar resources so that their potential future exploitation can be addressed. NASA plan to print, manufacture and build as much as possible goods from materials found on the Moon. This extraction and processing of local resources into useful products and services on another celestial body is referred as In-Situ Resource Utilisation (ISRU). Moreover, also ESA is working to understand the opportunities ISRU can offer to future exploration of Moon and to prepare through research, technology and missions. In addition China, Russia and India space programs started to be targeted on Moon also.

Besides materials the energy needed for this will be the key factor of the success for the future Moon and Mars bases. Fortunately, there is energy which can be used free of charge for the industrial exploitation - solar energy. Solar energy can be employed in specially designed solar furnaces at Moon, Mars or even zero gravity conditions for metallurgy of various metals and elements such as titanium and its alloys.

Therefore the main aim of this work is to summarise the results and knowledge obtained in this field during experiments with solar furnaces on Earth and propose design changes necessary for Space utilisation of solar energy in metallurgy of titanium.

\section{Earth experiments}

Average annual solar radiation arriving at the top of the Earth's atmosphere is roughly $1361 \mathrm{~W} / \mathrm{m}^{2}$ [2]. The Sun's rays are attenuated as they pass through the atmosphere, at sea level on a clear day when the sun is at the zenith direct radiation is about $1100 \mathrm{~W} / \mathrm{m}^{2}$.

On Earth surface sun concentrated solar power enables to produce high temperatures which at the focal point of solar furnace may reach $3500{ }^{\circ} \mathrm{C}$ (Fig. 1). This temperature is sufficient for melting of almost all types of materials. Recent experimental works [3-10] proved that the concentrated solar energy can be successfully used in the solar powder metallurgy of titanium, porous titanium, titanium alloys, surface treatment of titanium and compounds and even for welding of Ti6Al4V titanium alloy.

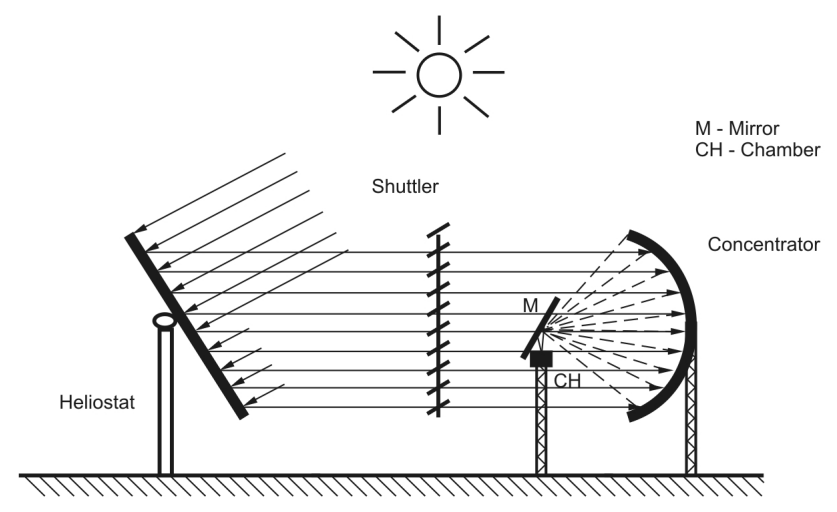

Fig. 1. Solar furnace for high fluxes - SF 40 at Plataforma Solar de Almeria, Tabernas, Spain.

Titanium foams were sintered by García et al. [3] in argon using $\mathrm{NaCl}$ as soluble spacer. Titanium foams (porosity between 58-77\%) were sintered at lower temperature and shorter time than in conventional furnace. Kováčik et al. [4] proved the possibility to use concentrated solar energy for sintering of titanium powder in argon atmosphere. Final porosity below $5 \%$ was achieved by varying the sintering temperature and time without 
applying of the external pressure. Solar sintering gave shorter time in comparison with the common vacuum furnace. Similar results were obtained for applicability of concentrated solar power for metallurgy of titanium [5].

Further, nitriding of pure titanium samples at high temperature with concentrated solar energy (Fig. 2) were performed in nitrogen atmosphere in the work of Kováčik et al. [6]. Significant decrease the heating time by the using of concentrated solar energy (average heating rate of $100 \mathrm{~K} / \mathrm{min}$ ) and creation of continuous and homogeneous surface nitride layer of high hardness, up to $2180 \mathrm{MHV} 1$ at $5 \mathrm{~min}$ solar treatment at $900{ }^{\circ} \mathrm{C}$, were observed. Similar results were obtained by Rodriguez et al. [7] for solar nitriding of TiAl4V titanium alloy. They observed maximum hardness of the solar nitrided TiAl4V samples $2100 \mathrm{HV}$ after treatment at $1200{ }^{\circ} \mathrm{C}$ for $15 \mathrm{~min}$.
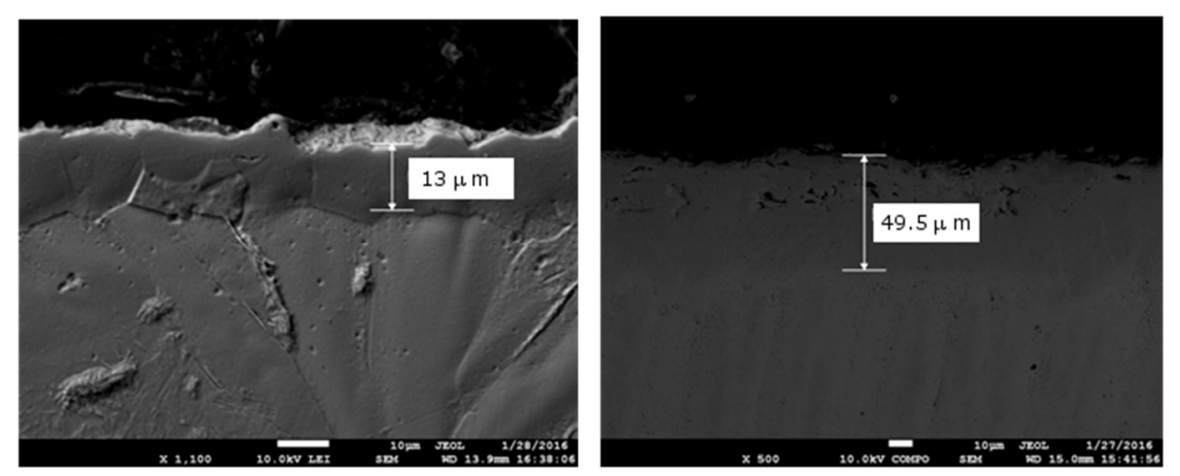

Fig. 2. Microstructures of titanium samples gas nitrided in solar furnace at 1 minute at $900{ }^{\circ} \mathrm{C}$ (left) and $1000{ }^{\circ} \mathrm{C}$ (right) and corresponding thickness of created TiN layers (SEM) [6].

From the mixture of $\mathrm{Ti}+15$ vol. $\% \mathrm{~B}_{4} \mathrm{C}$ powders $\mathrm{TiC}-\mathrm{TiB}_{2}$ ceramic foams were prepared by Kováčik et al. [8] via solar powder metallurgy using self-propagating high temperature synthesis (Fig. 3). Porosity of the prepared ceramic foams was $45 \%$. Ignition temperature of the self-propagating high temperature synthesis of foams was found around $1380{ }^{\circ} \mathrm{C}$ in the solar furnace. Romero et al. [9] successfully welded sheets of Ti6Al4V titanium alloy in the flush corner joint configuration in a controlled inert argon atmosphere.
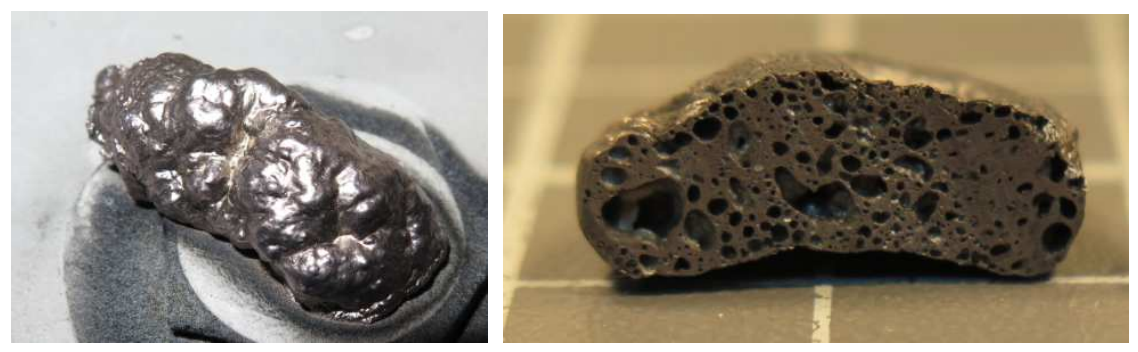

Fig. 3. $\mathrm{TiC}-\mathrm{TiB}_{2}$ ceramic foams prepared in solar furnace by high temperature self propagation synthesis in argon atmosphere ( $40 \%$ porosity).

Summarising, concentrating solar power enables shorter time of titanium production from titanium powder or titanium treatment in comparison with usual industrial sources of heat. Moreover, it belongs to the renewable energy sources, therefore gives lower carbon footprint to the produced goods. Further, the solar furnaces can be build according to real needs of production such as goods dimensions and required input power at optimal costs. Disadvantage of concentrated solar power is a necessity to use vacuum or protective atmosphere during titanium production. From industrial point of view it can be efficiently 
applied at countries of Earth solar belt with adequate resources of titanium ores. Unfortunately, the solar titanium industry is not developed yet [10]. Therefore King Fahd University of Petroleum \& Minerals, Saudi Arabia, in cooperation with IMMM and IVMA STU, Slovakia started works on creation of industrial equipments for solar powder metallurgy of titanium.

\section{Space design and recommendation}

\subsection{Moon}

In "Apollo", "Luna," and "Surveyor" landing sites [11] titanium was found present in the form of ilmenite ore $\left(\mathrm{FeTiO}_{3}\right)$. It was detected in basalts rocks (around $10 \mathrm{wt} . \%$ of titanium dioxide) and also in lunar regolith in particles ranging from fine silt to coarse sand. Clementine UV/V is camera filters and Moon Mineralogy Mapper (M3) on Chandrayaan-1 enabled to create detailed maps of $\mathrm{TiO}_{2}$ and $\mathrm{FeO}$ deposits on lunar surface [11]. This information gives basic points of interest at Lunar surface for ISRU of lunar titanium and iron. Therefore it will be possible to produce titanium powder or titanium sponge from ilmenite ore in reasonable efficiency using Kroll or Armstrong process, respectively.

Average annual solar radiation arriving at the lunar surface is more or less identical with irradiation on the top of the Earth's atmosphere $-1361 \mathrm{~W} / \mathrm{m}^{2}$ [2]. For this reason it can be expected that almost identical construction of solar furnaces can be used there as on Earth. The daytime on one side of the moon lasts about 13 and a half days (long enough to use concentrated solar energy for 4 days long warming of reaction tanks at $1100{ }^{\circ} \mathrm{C}$ during Kroll or Armstrong process of titanium production). During the day the Moon's surface temperature can reach $127{ }^{\circ} \mathrm{C}$ on equator. During night the temperature can go down to $173^{\circ} \mathrm{C}$. Therefore, the lunar solar furnaces need to withstand these temperatures. On the contrary due to lower gravity $(0.16 \mathrm{~g})$ the structures can be designed lighter as on Earth. If properly constructed, the parts of lunar landers, which will be in preliminary stays of Moon exploration left on the ground, can be reused also for the construction of the solar furnaces. Due to higher solar radiation per square meter and lower gravity also solar dishes (Fig. 4), which are simpler to build and operate than solar furnaces in Fig. 1, could be efficiently used on the Moon for titanium production. In addition, simple reflective foils can be used for the production of lunar dishes.

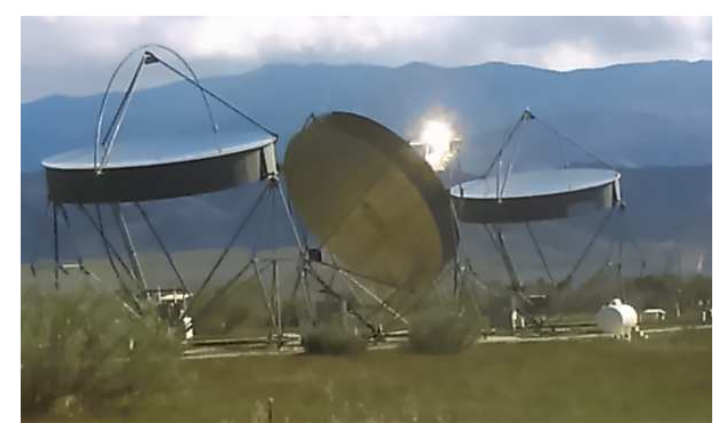

Fig. 4. Solar dishes at PSA, Tabernas, Spain. Middle dish is operating in Sun tracking position.

Vacuum on will is significant advantage for the sintering of titanium powder. Therefore no vacuum/gas chambers are necessary. Closed chambers are necessary only to trap the vaporised water from lunar regolith during mining of titanium ore and water at South pole craters. 
Concentrating solar power can be effectively used also to sinter regolith in expected landing sites as shown NASA experiments with sintering of tepthra at Hawaii testing site using concentrated solar power [12]. This will enable to avoid swirling of fine regolith dust that last for a long time. This can also solve problems with possible cleaning of mirrors/foils of solar furnaces from solar dust in the vicinity landing sites

ESA is also experimenting with the concentrated solar power. Project RegoLight is to further develop existing 3D printing technologies and methodologies for the purpose of 'sintering' and 'shaping' of lunar regolith using concentrating solar power [13]. Moreover, ESA did experiments on water deployment from lunar regolith using concentrated solar power [14].

Summarising, it seems very feasible and cost effective to use concentrated solar power for titanium and other metal and materials production on Moon.

\subsection{Mars}

The Mars landers Viking I, Viking II, Pathfinder, Opportunity Rover, and Spirit Rover identified aluminium, iron, magnesium, and titanium in the Martian soil [15].This indicates that future colonists can obtain from Mars a lots of necessary elements and materials to build colonies there effectively.

Average annual solar radiation arriving at the top of the Mars's atmosphere is roughly $590 \mathrm{~W} / \mathrm{m}^{2}$ [16]. The Sun's rays are attenuated as they pass through the atmosphere, the opacity is influenced by dust and therefore solar irradiation as low as $200 \mathrm{~W} / \mathrm{m}^{2}$ can be expected on Mars surface for concentrated solar power. As it is $5 \times$ less as on Earth, it will be necessary either to use arrays of heliostats (Fig. 5) to achieve required temperatures for titanium production or to use single very large structures. As Mars contains atmosphere vacuum/gas chambers ought to be used during titanium production. This will give extra costs to production similar as on Earth. Moreover, due to winds and dust storms lasting for long time protective covers ought to be built to protect whole solar furnace/ individual parts of solar furnaces against damage.

Summarising, it is probably not feasible to use concentrating solar power for titanium production on Mars at early stages of its colonisation.

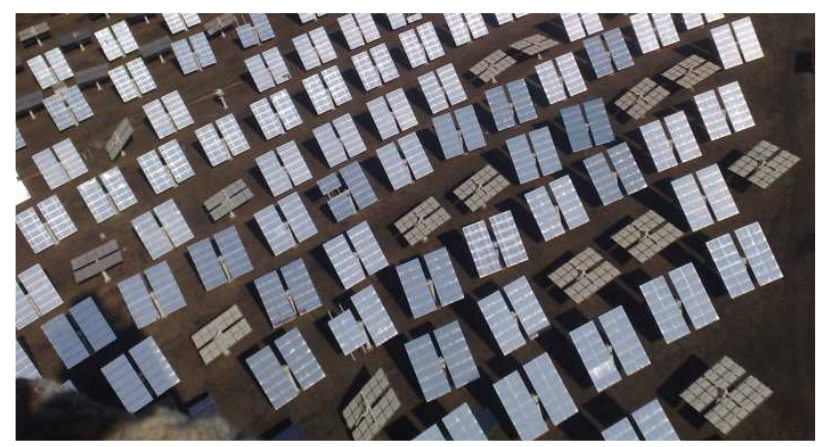

Fig. 5. An array of heliostats located near the solar power plant tower at PSA, Tabernas, Spain. Heliostats are of the size of $10 \times 10 \mathrm{~m}^{2}$.

\subsection{Main asteroid belt}

The composition of individual asteroids in the main belt is mostly unknown up to day. Composition is usually calculated from three primary sources: albedo, surface spectrum, and density of asteroids. It is expected that in main belt the proportion of C-type black 
(carbon based) asteroids is only about 40 percent [17]. The majority of asteroids are grey and principally made of silicate compound rock. This corresponds to type of meteorite found on Earth - the chondrites. Besides them, there are some asteroids that appear to be metal based, and there are metal meteorites found on Earth too. It indicates that it will be probably possible to find iron and titanium ore rich asteroids for titanium production.

After identification of such asteroid in main belt the problem will be very low solar radiation behind orbit of Mars (below $590 \mathrm{~W} / \mathrm{m}^{2}$ and is decreasing with the distance in power of -2). The construction of solar furnaces will be in this case dissimilar to Earth. Very probably the axial design of solar furnaces will be preferable. The furnace ought to be pointed directly to the sun permanently. The shutter will be needed to start/control/finish the operations automatically. It implies that the design could be very similar to design of Hubble space telescope - Newton optical design. Due to the distance from Sun significantly larger size and structures are needed to have enough power for titanium metallurgy. The large concentrators made from foils on simple structures can build on Moon orbit and sent to main belt.

For titanium production vacuum/gas chambers are not necessary, but they can be used to capture evolved gas/water at early stages of ore heating. Water can be used for oxygen and hydrogen production for habitats and fuel for rockets. During the final stages of the production rotation of whole furnaces will be probably necessary to create the gravity for the sintering of titanium goods.

In this case, the cooling may be a problem as in vacuum only radiation cooling takes place. Thus cooling could last for significantly longer time as on planets and moons.

Due to the large structure sizes the foil of concentrator can act as solar sail and effects connected with solar wind (displacement and rotation of furnace) will be necessary to compensate by rocket engines to keep the distance and focusing point to the Sun. Finally, multiple structures can be joined together to increase production capacity.

Another strategy is also possible: Lower irradiation and requirement of significantly large sizes can be overcome by building of specialized small scale orbital solar furnaces. They can be joined together to create Space factory. Space factory will also consist of refinery body with attached habitat and large cargo. After building on Earth\&Moon orbit Space factory can be sent to chosen asteroid in the main belt with required ore deposits. There cargo will be filled with the ore mined from asteroid. Afterward, Space factory with filled cargo will be driven on the orbit similar to Amor asteroids group orbits (Fig. 6). This orbit can be chosen with perihelion very close the Earth orbit.

By moving closer to the Sun the solar radiation will be increasing significantly, so smaller solar furnaces can be effectively operated in following sequence: At the beginning water and carbon dioxide will be produced at low power input of solar radiation. Somewhere around orbit of Mars metallurgy of titanium and other elements could take place. Finally, in the vicinity of Earth orbit, solar energy could be employed to split water to produce hydrogen and oxygen for fuels. After approaching near Earth orbit cargo ships could transfer the produced goods from Space factory to Earth and Moon orbital factories. Exchange of staff and necessary reparations cam be also realised there. Then all cycle could be repeated again. 


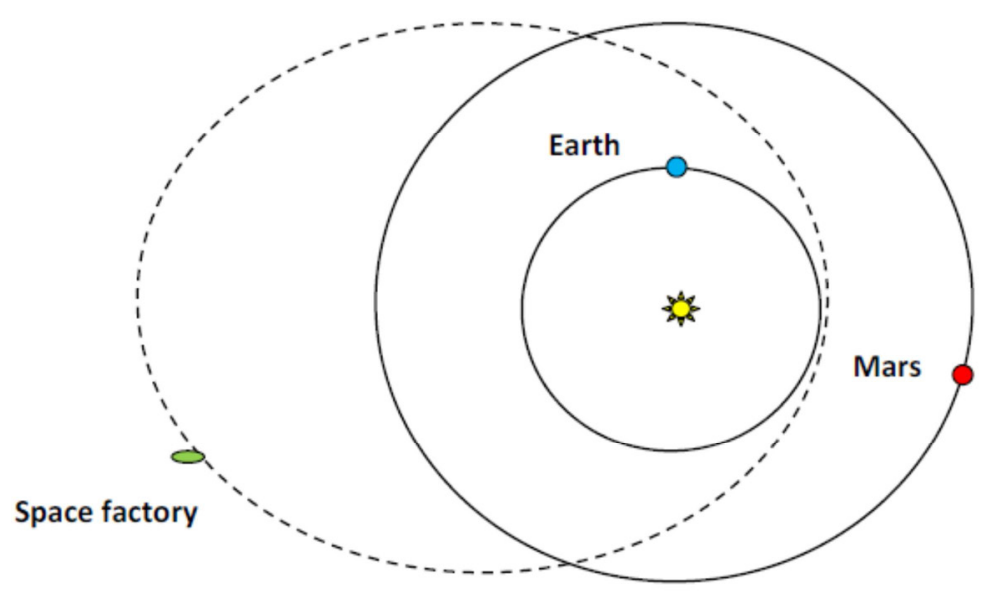

Fig. 6. Space factory orbit similar to the orbits of Amor asteroids in main asteroid belt.

Summarising, the technical solutions for space mining of titanium in main asteroid belt seems to be possible. Reconnaissance mission to find appropriate goods ores will be probably realised in the next future. Concentrated solar power could be used also in this case, but it ought to be used in optimal way.

\section{Conclusions}

After establishing of the Earth industry for solar metallurgy [10] of titanium the basic knowledge will be obtained for future Space application of concentrated solar power on Moon, Mars and in main asteroid belt.

Significant advantage for the sintering of titanium powder is vacuum present on Moon and in asteroid belt. On Mars the vacuum/gas chamber will be necessary to use.

Due to higher solar radiation per square meter and lower gravity also solar dishes could be efficiently used on the Moon for titanium production. Generally, it seems very feasible and cost effective to use concentrated solar power for titanium and other metal and materials production on Moon.

Solar irradiation around $200 \mathrm{~W} / \mathrm{m}^{2}$ can be expected on Mars surface. Therefore either arrays of heliostats needs to be used to achieve temperatures necessary for titanium production or single very large structures ought to be built. It will be also necessary to build covers to protect solar furnaces during Martian strong winds and dust storms. For this reason it is probably not feasible to use concentrating solar power for titanium production on Mars at the beginning of human colonisation.

In main asteroid belt are possible two strategies: The first strategy is to build very large solar furnace to concentrate enough of solar radiation near mined asteroid to be able to produce titanium. The second approach is to join smaller solar furnaces into large Space factory. This Space factory will be orbiting (similar to Amor asteroid group) between perihelion near Earth orbit and aphelion at the main asteroid belt. During orbiting to perihelion the solar radiation will be increasing thus enabling the water and gases extraction from mined ore, then extraction and metallurgy of titanium and finally hydrogen and oxygen production for rockets fuel.

Summarising, the technical solutions for space mining of titanium seems to be possible. Our further works will be to establish Earth industry for titanium solar production, 
to test the possibility of titanium producing from Moon ilmenite ore and to create cube satellite based solar furnaces at near Earth orbit.

This research was supported by the Slovak research projects VEGA 2/0044/17, and the project solved under the Program for the Support of Young Researchers: Young Researcher 2019, titled Study on Machinability of Ti Powder Materials by Laser. Financial support by the Access to Research Infrastructures activity in the 7th Framework Programme of the EU (SFERA Grant Agreement $\mathrm{n}$. 228296) is gratefully acknowledged. Financial support of the SFERA II project - Transnational Access activities (EU 7th Framework Programme Grant Agreement $n^{\circ}$ 312643) is also gratefully acknowledged. Finally KSA grant DF181016 at King Fahd University of Petroleum \& Minerals financial supports are also gratefully acknowledged.

\section{References}

1. https://www.nasa.gov/feature/nasas-exploration-campaign-back-to-the-moon-and-on$\underline{\text { to-mars }}$

2. O. Coddington, J. L. Lean, P. Pilewskie, M. Snow, D. Lindholm, Bulletin of the American Meteorological Society 97 (7), 1265-1282 (2016)

3. I. García, E. Gracia-Escosa, M. Bayod, A. Conde, M. A. Arenas, J. Damborenea, A. Romero, G. Rodríguez, Materials Letters 185, 420-423 (2016)

4. J. Kováčik, Š. Emmer, J. Rodríguez, I. Cañadas, Journal of Alloys and Compounds 695, 52-59 (2017)

5. J. Kováčik, N. Mináriková, T. Dvorák, J. Rodríguez, I. Cañadas, K. S. Al-Athel, P. Šugár, J. Šugárová, Š. Emmer, ChemEngineering 3, 84 (2019)

6. J. Kováčik, N. Mináriková, P. Šugár, J. Šugárová, M. Frnčík, M., Š. Emmer., J. Rodríguez, I. Cañadas, J. Kulasa, S. Malara, M. Lis, Mechanical Technology and Structural Materials 2017 (55), 65-70 (2017)

7. G. P. Rodriguez, G. Herranz, A. Romero, Applied Surface Science 283, 445-452 (2013)

8. J. Kováčik, T. Dvorák, Š. Emmer, J. Rodríguez, I. Cañadas, IOP Conference Series: Materials Science and Engineering 416 (1), 012032 (2018)

9. A. Romero, I. García, M.A. Arenas, V. López, A. Vázquez, Journal of Materials Processing Technology 223, 284-291 (2015)

10. L. G. Rosa, ChemEngineering 3, 83 (2019)

11. W. Zhang, Estimate of Lunar TiO2 and $\mathrm{FeO}$ with M3 Data. (In: B. Cudnik (ed.) Encyclopedia of Lunar Science. Springer, Cham, 2014)

12. T. Nakamura, B. Smith, 48th AIAA Aerospace Sciences Meeting Including the New Horizons Forum and Aerospace Exposition, 04-07 January 2010, Orlando, USA, doi.org/10.2514/6.2010-1162 (2010)

13. https://regolight.eu/

14. https://www.solarpaces.org/solar-reactor-makes-water-oxygen-on-moon/

15. A. G. Fairen, A. F. Davila, L. Gago-Duport, R. Amils, C. P. McKay, Nature 459, 401404 (2009)

16. J. Appelbaum, G. A. Landis, I. Sherman, Solar Energy 50, 35-51 (1993)

17. A. S. Rivkin, E. L. Volquardsen, B. E. Clark, Icarus 185 (2), 563-567 (2006) 